\title{
Involvement matters: BIM implementation at project level in the AEC industry
}

\author{
K. Bråthen ${ }^{1}$ \& A. Moum ${ }^{2,3}$ \\ ${ }^{1}$ Fafo, Norway \\ ${ }^{2}$ SINTEF Building and Infrastructure, Norway \\ ${ }^{3}$ Norwegian University of Science and Technology (NTNU), Norway
}

\begin{abstract}
In recent years enabling technologies such as building information modeling (BIM) has appeared in the architecture, engineering and construction industry. Despite that both the industry and researchers have devoted considerable resources in the development of numerous aspects of BIM, the fundamental implementation process at project level is still poorly understood. In this paper we investigate a real life project taken from Statsbygg, The Norwegian directorate of public construction and property. We use a theoretical framework to examine which factors are significant for successful BIM implementation at the project level. The case study deals with Statsbygg's request of using BIM and Lean-constructioninspired work principles in the design phase of a medium sized refurbishment project. The analysis finds that a successful implementation largely depends upon a participative and co-operative process. This means that significant project participants must be involved in a discussion of a BIM-implementation-plan which should reflect interests and goals of the involved parties.
\end{abstract}

Keywords: BIM, case study, change process, implementation, project level.

\section{Introduction}

The rapid development of information and communication technology has provided some new promising digital tools for the industry. In recent years enabling technologies such as building information modeling (BIM) has appeared. Here BIM is a term referring to three-dimensional computer-aided and productoriented design technologies and processes in the architecture, engineering and construction (AEC) industry. With the use of BIM a network of interdependent 
actors can collaborate to develop a model of the planned construction works [1]. In other words, in this paper, BIM is defined broadly as a process and technology. One of the most striking arguments for using BIM in the AEC-industry is that it has the potential to improve the collaboration among the actors involved in the building process which is expected to lead to increased efficiency, productivity and reduce costs. Despite that both the industry and researchers have devoted considerable resources in the development of numerous aspects of BIM, the fundamental implementation process is still poorly understood. Implementation of innovations such as BIM involves organizational change and is a demanding process [2]. Construction has some particular characteristics, which makes it different from other areas of industry. These characteristics are of importance for how organizational change is carried out. For instance, the construction industry contains numerous of different firms and professions. Construction projects are often organized as separate projects, with few standardized tasks, and rarely the same staff. Regularly people from different firms work together in one specific project, but will not work together again. This complexity is likely to be of importance for how BIM is implemented. Harty [3] points out that: "The complex context of construction work is characterized by inter-organizational collaboration, a project-based approach and power distributed amongst collaborating organizations". This means that the implementation of BIM at this inter-organizational level is placed beyond the control of a single actor who can ensure a unitary implementation and use of BIM [3]. Previous research has mainly studied implementation at industry or country level, or in a single firm. However, considerably fewer have studied implementation at the project level. By this we refer to examinations of "what is happening" when BIM is to be implemented into a project organization consisting of different firms. In this paper we want to map out different driving and restraining forces affecting the BIM implementation. The following research question will thus be examined: What factors were important for BIM implementation at the project level in the case scrutinized? This means that we are not going to study the effects or consequences of implementation, but rather examine how the actual implementation was done. By the term implementation we mean activities putting the use of BIM into effect.

In this paper an explorative case study from Statsbygg, The Norwegian Directorate of Public Construction and Property, is investigated. Statsbygg's field of responsibility is to provide appropriate, functional premises to public sector enterprises. This means that Statsbygg will provide guidance in the purchase and leasing of premises and, in respect of new buildings, act as building commissioner on behalf of the Norwegian government. The case deals with a refurbishment of a public building where Statsbygg acted as building commissioner. In this case Statsbygg requested the use of BIM including some Lean-construction-inspired principles in the design phase. In this case study, which later will be described in detail, Statsbygg took up a central role in the formulation of how BIM should be used in the project. This can probably be attributed Statsbygg aspiration to be driving force in the development of the Norwegian industry in several areas, BIM included. 
This paper is structured as follows: First, Lean-construction will be presented briefly, then the theoretical framework, as well as methodological considerations will be outlined. Next, the empirical material regarding the BIM implementation will be accounted for. Finally follows a discussion and some concluding remarks concerning the findings' generalizability.

\subsection{A short note on BIM and Lean-construction}

Above, BIM was said to be a term referring to three-dimensional computer-aided and product-oriented design technologies and processes [1]. Lean-construction can be defined as a "...is a way to design production systems to minimize waste of materials, time, and effort in order to generate the maximum possible amount of value" [4]. In this context it is important to emphasize that Lean-construction refers to the entire AEC-industry and not only the construction phase of a building project. Lean-construction and BIM are not dependent on one another i.e. Leanconstruction practices can be adopted without BIM, and BIM can be adopted without Lean-construction. Nevertheless, in earlier research and in this paper it is assumed that the potential for improvement of a construction project are enhanced when their adoption is integrated [5].

\section{What characterizes successful change processes?}

There exist many different theoretical perspectives on organizational change. The theoretical framework used in this article has not originated in one specific tradition, but is based on different studies and traditions. The framework used is to a large extent inspired by work done by colleagues in a number of studies of change processes both in public and private sector [6-8]. In these studies change processes has been analysed in different cases such as implementation of lean in ship building projects, new working arrangements in Norwegian municipalities as well as implementation of Last planner systems in the construction industry. It is a common assumption that managers have a special responsibility for change processes. However, it is more questionable whether there are always managers who in fact initiates and carry out the changes. Nevertheless, in the framework presented in this paper it is first and foremost a focus on manager's ability to carry out planned changes [9]. In this paper a BIM implementation (defined as both technology and process) will be looked upon as a change process. The applied framework does not give exact answers to how a change process should be carried out, but it rather consists of some factors that have shown to be relevant for whether a change process succeeds or not. The framework will be used to examine what factors have been prominent in driving or restraining the BIM implementation in the investigated case study. The framework consists of the following three factors: 1) a clearly stated purpose, necessity, and goals, 2) commitment, cooperation and involvement and 3) management support. Each of the factors will be discussed in detail in the next sections.

The first factor, a clearly stated purpose, necessity, and goals have shown to be of crucial importance in several studies. This factor is partly about communicating 
to all actors involved in the change process what should be done and why it should be done. Changes that are perceived as important and necessary by managers, enthusiasts, R\&D units, etc. are not always viewed in the same way by the "troops on the ground". Central in this context, is that it exist a general agreement on that something ought to be done [10]. A clearly specified purpose and a perceived need for change are consequently essential for the involved actors' motivation in a change process, but also to be able to formulate operationalizable and achievable goals [11]. Although the main purpose of a change may be clear i.e. the introduction of BIM, it is also important that those who are involved and affected by the change have a meaningful understanding of the goals for the initiative. This is a prerequisite for both support and legitimacy and to increase the possibilities for those involved to be goal-oriented. A well-known pitfall is vaguely formulated goals, making it difficult for the involved parties to work targeted. Another danger if the goals are not formulated sufficiently clear is that it could lead to a form of false agreement - agreement based on an ambiguous content. Concerning this study, a clearly stated set of goals, is about formulating specific goals for how the BIM to be used in the project. This may be e.g. goals about to how to work with the BIM, how to make different types of checks etc. In other words, it is important having operational goals which the parties involved can work towards.

The second factor is about commitment, cooperation and involvement. One of the most essential aspects for a successful change is establishment of employee commitment. This has been particularly essential within the Norwegian context, where the idea of employee involvement and participation has been significant for a long time [12]. Commitment is about acceptance of the content of a change process by all involved actors, leaders as well as people on the ground. Commitment can be formalized through written formal agreements such as contracts and other forms of agreements. But just as important is what we can label as a form of "social approval" by the affected parties. This is about a positive assessment of the change processes and an acceptance and support of both goals and strategies. It is in other words not only those participants who have formally undertaken to use BIM, but also about the different actors' acceptance and adherence to goals and strategies. Involvement often provides greater legitimacy and an opportunity to deal with positive opposition and prevent destructive opposition. This is about getting all involved parties engaged in the implementation process. This requires a general agreement on the goals and conformity between goals and means. Involvement is to a large extent about information, communication, participation and influence. It is crucial to involve affected actors and listen to their opinions and allow them to have an impact on the process [13]. This is particularly significant when it comes to the use of BIM in project organizations due to actors across organizational boundaries that are set to work together towards common goals.

The third and last factor is management support. It is significant that leaders in a change process motivate to keep up the work for working further efforts. This could be done by showing interest, requesting "results" and in this way keep up the pressure for change. Management support is in other words important to 
provide legitimacy for the change process but also to ensure access to essential resources such as equipment and training, see e.g. [9].

To sum up this theory section, with the current level of "BIM maturity" implementation frequently involves a process of change. This kind of implementation has little to do with specific concepts or techniques. It can rather be seen as a "general" organizational change process that requires a development strategy and commitment and participation from all actors as well as management support. Change process without such a basis is likely to fail [8].

\section{Methods}

In this paper we investigate a BIM implementation process at the project level to gain knowledge about the factors that were important in this process. To shed light onto such a complex phenomenon, a case study seems like an appropriate strategy. According to Yin [14], a case study consists of an in-depth inquiry into a specific and complex phenomenon, set within its real-world context. Case studies are seen as suitable to answer "how" and "why" questions and allows for the investigation of many variables consequently generating in-depth knowledge. This case study is based on qualitative data which are generated from semi-structured interviews with leaders and "hands on" project participants; this includes both people from Statsbygg and the design team. The purpose of the interviews was to get informants' own assessments of the project and how the implementation and planning of BIM had occurred. Consequently, all quotes used in this paper are translated from Norwegian to English by the author. As a part of the data collection we also observed several types of meetings, i.e. design meetings and different types of plan meetings. Observational studies involve making field notes based on a detailed observation of behaviour, talk, interaction, practices etc. In this study we have chosen a non-participant strategy. Such a strategy implies that we were not a part of the activity taking place at the meetings, but simply visible observers. In addition documents have been used as a supplement to other data types generated through interviews and observation.

\section{The case: BIM implementation at the project level}

First in this section, Statsbygg's role in the Norwegian construction industry will be discussed. Secondly, the empirical material of the BIM implementation process will be presented.

\subsection{Prolog: the case company and project organization and the SamBIM research project}

Statsbygg has a large area of responsibility which includes acting as a building commissioner. Statsbygg has for a long time been a driving force on the use of BIM in the Norwegian construction industry. Already in 2008 Statsbygg launched its first BIM manual and the same year they demanded the use of BIM in a pilot project in western Norway. Statsbygg has ever since been a premise setter in the 
development and implementation of BIM in the Norwegian industry. Statsbygg is also one of the industry partners in an ongoing Norwegian research project called SamBIM (Collaboration with BIM as a catalyst) financed by Norwegian research council. This research project is based on a joint effort of Norwegian industry and research partners. In this project several actors from the construction industry wants to try out new forms of organization and technologies such as building information models. The aim of the project is to increase value creation and innovation in the society, the AEC-industry and the companies involved by developing and improving BIM-supported processes and collaboration in real-life projects. The case study that forms the basis for this paper was one of Statsbygg contributions to this research project. This project was chosen by Statsbygg because it was supposed to start up in appropriate time, and that project management wanted to participate.

In the following sections we will take a closer look at the implementation of BIM including some Lean-construction inspired methods in a construction project where Statsbygg acted as the building commissioner. The case deals with a refurbishment of a public building in Oslo. The building was constructed in 1974 and has remained largely unchanged since that time. The project involved construction of $1700 \mathrm{~m}^{2}$ and rehabilitation of $4900 \mathrm{~m}^{2}$.

\subsection{Elevated BIM ambitions}

"We wanted to try out 'something more in this project' - we had higher BIM ambitions than usual" (Statsbygg employee).

Already in the pre-design phase, it was decided by Statsbygg that this project should be a part of the SamBIM research project. As a result of that decision, Statsbygg wanted higher BIM ambitions than normal for the design phase (the schematic and preliminary part of the design phase according to the Statsbygg projection model). After the project was out to tender, some of the project members from Statsbygg suggested that as a part of the elevated BIM ambitions, it would be interesting to try out some Lean-construction-inspired principles in the design phase as a part of the BIM-plan. This was certainly not enshrined in the tender documents which were sent out some weeks in advance. Basically, the idea was to try out co-location of the design team a few times week in a common office together with some working methods based on "lean thinking". The latter was not particularly specified or discussed in Statsbygg at that time. However, these thoughts about co-locating the design team together with some new working methods represented something new for Statsbygg. At that time Statsbygg was more or less unfamiliar with this kind of working, but still something they wanted to get more experiences with from their perspective as a building commissioner. Especially they wanted to gain more knowledge about whether such workings methods could lead to a better and faster design process.

Based on a competitive tendering a design team was selected. The chosen design team was a constellation of several small and medium sized Norwegian firms based in the Oslo area. In interviews, Statsbygg has explained that this group was chosen largely based on their extensive BIM knowledge. The proposed solutions, the team's previous experience and the cost level also played a role in 
the decision. After the contract was signed and project was started up, Statsbygg arranged several meetings where issues relating to the project in general and the use of BIM specifically were discussed. Those meetings were initiated by Statsbygg's project manager and assistant project manager, as well as so-called change agent. The change agent was a Statsbygg employee who had a special responsibility for SamBIM's activities internally.

\subsection{Co-location and deciding of the new working methods}

In one of the first meetings the design team was presented to Statsbygg's aspiration to try out co-location of the design team in a common office as part of the BIMplan for the project. In this meeting Statsbygg presented the suggestion in an openended way. Put another way, Statsbygg did not come up with any set options on how this should be done. Rather, they welcomed an open and involving discussion with the design team on how the co-location could be done and how the working plan could be set up. This proposal was mainly well-accepted by the parties involved, and after some meetings Statsbygg and the design team agreed to try the following BIM-plan for the design phase:

The design team and representatives from Statsbygg was going to be co-located one to two days per week in an office close to one of the architect's office. This form of working was according to several of my informants inspired by Leanconstruction and principles taken from so-called Virtual Design and Construction (VDC). VDC is a label used by the CIFE center at Stanford University for a concept partly influenced by Lean-construction. It exists several touch and overlaps between Lean-construction and VDC methods. An important common feature is the focus on activities that bring value to the project and minimize waste activities, a focus on pull mechanisms and "place the customer in the center", to name a few similarities. A variety of methods and techniques have been developed under the "VDC-umbrella". Two Lean-constructions tools or methods originating from VDC was planned to be used in this case, namely Integrated Concurrent Engineering (ICE) and big room-organization. ICE involves co-located, parallel design sessions where central goals include better collaboration, faster schedules and better quality. With so-called ICE sessions, all relevant actors are gathered in a big room where they work simultaneously using computers, common databases and SMARTboards. In this case the big room was planned to be furnished with desks around a SMARTboards in a relatively large open office. In addition it was planned to furnish two adjoining offices for separate meetings, phone calls etc. As a part of the BIM-plan which included co-location, Statsbygg and the design team agreed upon a weekly schedule. The weekly schedule meant that every Wednesday all disciplines should be present when asked for or clearly needed, on Thursdays everyone in the team and the representatives from Statsbygg as the owner should be present the whole day. Additionally, on some Thursdays the team also intended to have meetings with the user's representatives.

The intention with this form of working was to strength the interdisciplinary collaboration and to speed up the design process and reduce response latency. As part of the try out, the design team and Statsbygg planned to use a planning tool, a so-called planning matrix. The matrix was planned to function as a schedule 
between the co-located meetings. The matrix consisted of a whiteboard organized by disciplines, dates and activities. Post-it notes in different colors should be used to allocate tasks. In relation to this planning tool it was also planned to use something usually referred to as "action items". Action items are created during meetings when it is discovered that some kind of action is needed. The action required is then documented as an action item and assigned to someone, usually a member of the group. The person to whom the action is assigned to is then obligated to perform the action and report back to the group on the results. The team hoped that the planning matrix combined with the use of action items should lead to an effective planning and execution of the design phase with BIM.

\subsection{Creating the rules of the game}

As a part of the meetings between the design team and Statsbygg, the different actors had several discussions about what could be referred to as ground rules for working. By ground rules we simply mean guidelines for how the team envisioned how they should work together. One of the meetings was organized and labeled as a "collaboration workshop". This workshop was arranged before the project formally started. The purpose of this workshop could be said to be twofold. The workshop was partly about the design team doing a practical exercise to solve some technical challenges regarding to interoperability, exchange software tips, etc. But this was also about defining more specifically how BIM should be used in the project. Perhaps more important, the intention of the workshop was also about working out a "collaboration strategy". In an interview, one of the informants from Statsbygg emphasized that this strategy was not a pure "BIM strategy" in the traditional manner. The central distinction between BIM strategy and collaboration strategy according to the informant was that the latter should focus more on the "social sides" of collaboration; How the actors should act together - the rules of the game - and not just the technical parts of BIM. A central part of this strategy was to assign responsibilities and let everyone in the team know their role, what it entailed, and how it is related to the needs of the rest of the team. This was about raising awareness to that even though the team consisted of individuals who had much knowledge of BIM, it did not necessarily mean that it constituted a brilliant design team. To use a metaphor from the sports: Regardless of individual talents, a "dream team" needs a decent tactical plan to benefit from the individual skills.

\subsection{Epilog: The project got a quick end}

"[I had] expectations for the big room. Too bad we did not get chance to try it out in full" (member of design team).

The quote above is from an interview with one of the designers and illustrates the projects fate. When the project had been going on for some months and the participants had gained some experience with the working methods, the project was terminated by Statsbygg's principal. This was done due the lack of financial appropriations over the central government budget, and consequently not for reasons associated to the project per se. This makes it difficult to say anything 
about effects or results of the successful BIM implementation. However, this is not the purpose of this paper.

\section{Discussion}

In the next sections, the theoretical framework will be used to examine what factors have been prominent in driving or restraining the BIM implementation in the case study presented in this paper. The framework will hopefully help to shed light on some of the factors which was important for the successful outcome.

All interviewed actors had some experience with BIM from previous projects. Most of the informants were therefore quite aware of what kind of benefits the use of BIM could bring. Based on the interviews it seems clear that the vast majority of the design team had a good understanding of why BIM should be used and it should do in this project. The projects purpose and goals connected to BIM was specified to a certain extent in the Statsbygg BIM-manual and tender documents. These topics can partly be found in the first factor in the theoretical framework, about having a clearly stated purpose, necessity and goals. However, considerably fewer in the design team and Statsbygg's people had any experience with Leanconstruction and VDC methods. In interviews and observations of meetings the informants stated that in the early stages of the design phase, it was some uncertainty about what co-location meant in practice. As described in the empirical section of this paper the ideas linked to co-location was something that came up more or less by a coincidence internally in Statsbygg; the co-location were presented as an alternative approach to work with BIM after the job was put out to tender. In the interviews some of the informants from the design team were critical to the fact that this was not specified in the contract documents. However, the data shows that BIM in combination with the new working methods was considered interesting because such methods were thought to be "the next big thing" by the design team. Despite little formalized information about purpose, goals etc. the working methods were perceived as innovative and consequently something the design team wanted to try out. In some of the interviews it was pointed out that neither Statsbygg nor the design team had any clear vision about this new work method, beyond hoping it would lead to better collaboration and faster design phase. Despite some initial critical remarks, the data indications that it was established an early consensus about implementing BIM including the innovative working methods. This can probably partly be attributed to the fact that team had a good knowledge of some parts of BIM from previous projects. However and just as important as the knowledge level, the data indicates that willingness to implementation can be linked to the design teams extensive participation and co-determination in the process of defining what and how it was actually going to be tried out. This is in accordance with the second factor in the theoretical framework, which is about commitment, cooperation and involvement. This means that the team itself together with Statsbygg was given the opportunity to formulate how the design phase should be organized as well as deciding the "rules of the game". This was done in the initial meetings, before the actual work had started. Two informants put it this way: 
"The collaboration workshop was very good. We got a nice discussion on some technical challenges. The meetings where we discussed how this 'VDCthing' should look like were crucial. I think we came up with a pretty good solution" (member of design team).

"We did not have any clear perception on how this was going to be. We had some general thoughts, but nothing specific. I think it was a good thing that everyone contributed to the plan" (Statsbygg employee).

In this involvement process Statsbygg's project manager and assistant project manager, as well as the change agent played a key role. Those persons, who all can be said to have a managerial role in the project, took initiative and opened for a participatory process. In this process ideas and suggestions was welcomed and had a real impact on the final decision about how the design phase should be organized. Those three persons also played an important role for motivating the involved actors to come up with ideas and drive up the pace. They also played a significant role in providing the project with extra financial resources in order to finance hiring of the big room facilities, access to internet, buy SMARTboards etc. These issues are in accordance with the frameworks third factor which underscores the importance of managerial support for a successful change.

Our informants claimed that the implementation process should be considered as successful because Statsbygg and the design team succeeded to put BIM into effect. Based on this assessment the analysis finds that a successful implementation of BIM depends more or less upon all the three factors specified in the theoretical framework. In the case, factors related to commitment, cooperation and involvement, as well as managerial support appear to be the most prominent. Managerial support was in this case important for motivation and for providing financial resources. The analysis also finds that a successful implementation of BIM depends upon a participative and co-operative process. This means that project participants must be involved in a discussion on how BIM should be implemented and used. The analysis points out that these kinds of discussions and can ensure the needed support for an innovative and unfamiliar BIM-process.

Even though the theoretical framework points out some important factors, it is nevertheless reasonable to assume that some other factors also may have had an impact on the successful implementation of BIM. In the following, we will briefly discuss two other possible factors. The first factor is about the importance of "enthusiasts", while the other factor deals with Statsbygg's distinctive role in the Norwegian construction industry. By the term enthusiast we mean persons who are characterized by their "passion for the sake" and for being a driving force in the process. In the observational studies and in some of the interviews we were told about a couple of persons from Statsbygg and the design team who had played a significant role in the implementation process. These individuals were particularly innovative and knowledgeable individuals who willingly shared their insight with others and were important partakers in driving the process forward. Despite the fact that these persons' influences are not captured by the theoretical framework, their vital role for successful BIM implementation should not be underestimated. Secondly, the projects status as a research project connected to 
SamBIM may also have had an impact on the result. The encouraging basis of being part of a large research project may have contributed to the positive view on the project by the involved actors as well as led to higher efforts. Certain parts of our data material indicate that several participants found it interesting to be part of a pioneering project such as this. Additionally, the fact that Statsbygg is an important actor in the Norwegian construction industry may also have led to a more well-disposed design team compared to a situation with a building commissioner being of lesser importance. The desire of having a good relation to Statsbygg should probably not be underestimated.

\subsection{Concluding remarks}

The analysis finds that a successful implementation depends upon a participative and co-operative implementation process at the ground level. Without involvement and participation organizational change and development will probably be met indifference and apathy or at worst resistance. This is in accordance with other studies in the construction industry [8] as well as other industries and the public sector. Based on this we regard the importance of participation and involvement for successful organizational change as a somewhat robust findings. Due to the construction industry's characteristic features, e.g. inter-organizational relationships and project-based work, aspects related to participation and cooperation seems avoidable in change processes and organizational development. This implies that significant project participants should be involved in a discussion of a BIM-implementation-plan which should reflect interests and goals of the involved parties. The analysis points out that these kinds of discussions can ensure the needed support for an innovative and for some unfamiliar BIM-process. Consequently, the findings of the case study indicates that it does not exist a generic best practice way of implementing BIM. Instead each process must be tailored by the involved actors through involvement and participation. This may imply that BIM implementation at the project lever in the AEC-industry without such basis is more likely to fail rather than to succeed. However, further research from other projects and countries is needed in order to provide a clear answer to this question.

\section{References}

[1] Taylor, J.E. \& Bernstein, P.G., Paradigm trajectories of building information modeling practice in project networks. Journal of Management in Engineering 25(2), pp. 69-76, 2009.

[2] Moum, A., Exploring Relations between the Architectural Design Process and ICT Learning from Practitioners Stories, NTNU: Trondheim, 2008.

[3] Harty, C., Innovation in construction: a sociology of technology approach. Building Research \& Information, 33(6), pp. 512-522, 2005.

[4] Koskela, L., Howell, G., Ballard, G. \& Tommelein, I., The foundations of lean construction (Chapter 14). Design and Construction: Building in 
Value, eds. B. Hellingsworth, R. Best, \& G. de Valence, ButterworthHeiemannn: Oxford, pp. 211-226, 2002.

[5] Sacks, R., Koskela, L., Dave, B. A., \& Owen, R., Interaction of lean and building information modeling in construction. Journal of construction engineering and management, 136(9), pp. 968-980, 2010.

[6] Moen, S.E \& Moland, L.E. BygningsInformasjonsModellering (BIM), Faforeport 2010:31: Oslo, 2010.

[7] Bråthen, K., Moland, L.E. \& Berg, T.F., Trafikkstasjonen på Risløkka. Samhandling med BIM i prosjekteringsfasen. Fafo-report 2014:09: Oslo, 2014.

[8] Skinnarland, S. Use of progression planning tools in developing collaborative main contractor subcontractor relationships in Norway. Heriot-Watt University: Edinburgh. 2013.

[9] Jacobsen, D.I., Motstand mot forandring, eller: 10 gode grunner til at du ikke klarer å endre en organisasjon. Magma, 1(1), pp. 9-25. 1998.

[10] Kotter, J P., Leading change, Harvard business school press: Boston, 1996.

[11] Cummings, T., \& Worley, C., Organization development and change. Cengage learning: Stamford, 2014.

[12] Thorsrud, E. \& Emery, F., Industrielt demokrati. Universitetsforlaget: Oslo, 1964.

[13] McGregor, D., The human side of enterprise, McGraw-Hill: New York, 1960.

[14] Yin, R. K., Case study research. Design and methods. Sage: London, 2003. 